This item was submitted to Loughborough's Research Repository by the author.

Items in Figshare are protected by copyright, with all rights reserved, unless otherwise indicated.

\title{
Interdisciplinary geographies of science
}

PLEASE CITE THE PUBLISHED VERSION

http://dx.doi.org/10.1007/978-90-481-8611-2

\section{PUBLISHER}

(C) Springer Science + Business Media B.V.

\section{VERSION}

AM (Accepted Manuscript)

\section{PUBLISHER STATEMENT}

This work is made available according to the conditions of the Creative Commons Attribution-NonCommercialNoDerivatives 4.0 International (CC BY-NC-ND 4.0) licence. Full details of this licence are available at: https://creativecommons.org/licenses/by-nc-nd/4.0/

\section{LICENCE}

CC BY-NC-ND 4.0

\section{REPOSITORY RECORD}

Jons, Heike, David N. Livingstone, and Peter Meusburger. 2019. "Interdisciplinary Geographies of Science". figshare. https://hdl.handle.net/2134/16199. 


\section{Please cite this paper as follows:}

Jöns, H, Livingstone, DN, Meusburger, P (2010) Interdisciplinary geographies of science. In Meusburger, P, Livingstone, DN, Jöns, H (ed) Geographies of Science, Springer, pp.ix-xvii, ISBN: 9789048186105. DOI: 10.1007/978-90-481-8611-2.

\section{Interdisciplinary Geographies of Science}

Heike Jöns, David N. Livingstone, and Peter Meusburger

More than two decades into the "geographical" turn within science studies (Shapin, 1998, pp. 5-6), geographies of science are a vibrant interdisciplinary field of research. Based on exciting work by geographers, historians, sociologists, and anthropologists of science, the ideas that science has a geography and that scientific knowledge bears the marks of particular locations have themselves become accepted facts, at least within this community of scholars. Indeed, it can be argued that the meaning of scientific knowledge "takes shape in response to spatial forces at every scale of analysis - from the macropolitical geography of national regions to the microsocial geography of local cultures" (Livingstone, 2003, p. 4).

Instead of marveling at the apparent universality and "placelessness" of scientific knowledge, scholars interested in the geographies of science have focused on the specific circumstances of scientific practices and on the ways in which the travels of scientists, resources, and ideas shape the production and circulation of scientific knowledge. They also examine how and why the interpretation of certain knowledge claims may change in different times and places. The variety of research topics and approaches addressed within geographies of science is documented in a number of reviews that emphasize the 
long-standing mutual enrichment of research carried out in geography and other fields that contribute to interdisciplinary science studies (Finnegan, 2008; Livingstone, 1995; 2003; Meusburger, 2008; Naylor, 2005; Powell, 2007; Shapin, 1995, 1998; Withers, 2002).

A defining moment in this reciprocal relationship is captured by Livingstone's (1995) outline of a "historical geography of science" that explores the contributions Michel Foucault, Clifford Geertz, Anthony Giddens, Donna Haraway, Bruno Latour, Edward Said, and others have made to the conceptualization of a distinctively geographical interest in scientific knowledge and practice. Shapin (1998) responded that "[s]tudents of science owe much to geographers and it is flattering to learn that Livingstone thinks that historians of geography might possibly learn something from us. If so, it is mainly through showing some of the possibilities inherent in geographical work" (p. 6). This conversation between geography and science studies has continued to flourish ever since. It has not only produced a series of commentaries on the value of social constructivism and actor-network thought for the geographies of science (e.g., Barnes, 1998, 2001; Bravo, 1999; Demeritt, 1996, 2006; Harris, 1998; Jöns, 2006) and for human geography more generally (e.g., Bingham \& Thrift, 2000; Murdoch, 1997) but has also inspired substantial monographs (e.g., Ash \& Cohendet, 2003; Driver, 2001; Livingstone, 2002; 2003; Whatmore, 2002; Withers, 2001), comprehensive anthologies (e.g., Simões, Carneiro, \& Diogo, 2003; Smith \& Agar, 1998), and a number of special journal issues (e.g., Anderson, Kearnes, \& Doubleday, 2007; Castree \& Nash, 2006; Naylor, 2005; Philo \& Pickstone, 2009; Roe \& Greenhough, 2006). Among the most recent outcomes are the seminar series and online reader entitled Locating Technoscience (UCL, 2008) and the "Knowledge and Space" symposia and book series, of which the present collection of essays is the third volume. 
Aiming to further advance interdisciplinary geographies of science through conversations between scholars working in different academic fields, this volume explores the benefits of a geographical perspective on scientific knowledge and practice from the perspective of geographers, sociologists, historians, anthropologists, and scholars of architecture. A comparison of their contributions both discloses how different disciplinary settings exert their influence on framing research designs in distinct ways and indicates a common concern for the spatial relations of scientific knowledge and practice. The book presents a balance of historical and contemporary case studies, with most of the essays centering on European practices. However, some of the chapters provide global perspectives, whereas others deal with African practices and American indigenous knowledges. Keeping in mind that one of the most significant insights into the spatiality of knowledge production is the partiality of all knowledge claims (Haraway, 1988), we note that the following peer-reviewed essays inevitably provide very specific perspectives on the geographies of science. These chapters add to a growing body of work yet also raise important questions for future research.

This volume stresses four main topics, each of which is represented in a corresponding section. The first, "Comparative Approaches to Scientific Knowledge," gives two fairly general accounts — one by historical geographer David N. Livingstone (Chapter 1) and the other by sociologist Nico Stehr (Chapter 2). Aiming to further develop the agenda of geographical science studies, Livingstone delineates the overall context for this set of essays. He begins by reviewing ways in which space has become a central organizing principle for examining the production, circulation, and consumption of scientific knowledge, stating that scientific sites and spaces, the movement and transformation of knowledge, and scientific regions ranging from the provincial to the continental have been significant foci of research. Livingstone then discusses how 
geographies of science have challenged long-standing polarities such as the natural and the social, the local and the global, and the scientific and the political. He also outlines the benefits of bringing materialities of science to center stage, pointing out that scientific knowledge resides in bodies, buildings, and other physical objects. Lastly, Livingstone elaborates on four spatial themes for future research: the agency of landscape, political ecology, print culture, and speech space.

Stehr approaches the spatiality of knowledge from a slightly different angle by discussing the idea of "global worlds of knowledge." Interestingly, however, he arrives at a conclusion not altogether different from Livingstone's notion of geographically diverse landscapes of knowledge. Stehr distinguishes between the horizontal integration of knowledge (meaning the proliferation of sites of knowledge production and consumption) and the vertical integration of knowledge (meaning the relationship between expert knowledge and everyday knowledge across social worlds). On this basis he reasons that globalizing worlds of knowledge may partially exist as "normative speculations, by decree, as a thought experiment, or as a business plan" but that the challenges and constraints are far too large for anything like a comprehensive global world of knowledge to emerge.

This book's second section, "Mobilities and Centers," is written by geographers. It draws attention to the circulatory spaces of science by examining how transient and more permanent moves of scientists and scholars between different sites of academic knowledge production have contributed to the formation of scientific centers. Studying the career paths of eminent scientists in Europe, Peter J. Taylor, Michael Hoyler, and David M. Evans (Chapter 3) identify the shifting geographies of European knowledge centers and their networks from the sixteenth to the nineteenth centuries. Interpreting scientific practice as a core-producing process in Wallerstein's (2004) modern world- 
system, the authors assert that studying the work places and career moves of scientists yields information about the two types of social space identified by Castells (1996): spaces of places and spaces of flows. The resulting geohistorical patterns of European knowledge nodes and networks provide a unique macroperspective on the "rise of modern science" that simultaneously offers an argument about why so many European scientific centers did not become major cities.

Peter Meusburger and Thomas Schuch (Chapter 4), too, use data on the career mobility of scientists and scholars, tracking the rise of Heidelberg University to the ranks of internationally renowned research universities in the late nineteenth and early twentieth centuries. They illustrate how that trajectory is mirrored in the changing social background of Heidelberg's professors; the age at which they reached different career stages; and the growing diversity of the places in which they were born, received their doctoral and postdoctoral degrees, and became professors. The authors hold that Heidelberg University's favorable working environment in the nineteenth century-due to effective reorganization and financial support by the state, broad university autonomy, freedom of thought, and an accommodating political climate-permitted increasingly selective recruitment policies targeting renowned professors at the peak of their careers. Consequently, Heidelberg's full professors were often highly mobile individuals who had worked in a variety of cultural environments, a situation that reveals how the openness to drawing faculty from geographically diverse places nurtured the formation of an important scientific center.

Heike Jöns (Chapter 5) examines a more transient circulation of academics by looking at the ways in which a growing emphasis on academic travel for purposes of research, visiting appointments, lecturing, conferences, and consulting contributed to transforming Cambridge University into a modern research university. She 
conceptualizes circular academic mobility as a twofold mobilization process in Latourian "centers of calculation," namely, the home institutions and the host institutions. This perspective sheds light on how, from the 1890s onward, the temporary recruitment of Cambridge expertise in the United States - mainly through visiting appointments and lecture tours - gradually turned American universities into new global scientific centers and fostered the development of an Anglo-American academic hegemony in the twentieth century.

The third section of this volume, "Designing Knowledge Spaces," discusses four attempts to create distinct spaces for knowledge production and consumption. Historian Dominik Collet (Chapter 6) examines the endeavor by the fellows of London's Royal Society to establish their own museum for research and the display of specimens in the second half of the seventeenth century. Interrogating Lux and Cook's (1998) hypothesis that weak, but flexible, "open networks" were crucial for scientific progress in early modern times, he shows why the fellows' truly global network of correspondence supplied a number of objects regarded as "exotic curiosities" but produced scientifically rather unsatisfying results. The author contends that unreliable, uncooperative colonial contacts and the disparate information of poor quality that often reached London via routes different from those traveled by the material objects themselves made it impossible to gather the contextual information required for serious scientific research. Without such an intact Latourian "circulating reference" between the museum's specimens and their places of origin, the Royal Society's widespread open networks failed to spur scientific progress and thus restricted the collection's function to the preservation and presentation of curiosities.

Albena Yaneva (Chapter 7), a sociologist and ethnographer working in the field of architectural studies, draws attention to contemporary buildings conceived for scientific 
practice. She critically examines recent efforts to design attractive atria intended to facilitate social interaction and generate creative encounters beyond confined laboratory spaces. Starting with a discussion of design principles for recent laboratory spaces, she maintains that the emphasis on the atrium is a response to the challenge of enhancing the potential for collaborative research and networking between human and nonhuman actors across disciplinary boundaries. Her examples explain how the atrium became an "important interactive space"; a "social core" with multiple bridging functions; a transdisciplinary "mixing chamber" of researchers, objects, and ideas; even "a complex knot of a quasi-urban network" in city-shaped buildings that correspond to the complex research tasks at hand. Although not all of the innovative designs have been popular with scientists, the realities arising from the discussed projects for improving academic working environments starkly contrast those of most such work places, which are too often characterized by the much less socially conducive campus architecture of the 1960s and 1970s.

The contribution by sociologists Wesley Shrum, Ricardo B. Duque, and Marcus Antonius Ynalvez (Chapter 8) suggests, however, that some scholars and scientists may find architecture's inspirational qualities less important than what they consider to be basic, functioning e-mail and Internet infrastructure at the university. This impression is conveyed by the authors' hitherto unsuccessful attempt to facilitate Internet connectivity in a Ghanaian research institute. The story of this project, which turned attention to what the authors called the "outer space of science," was presented in Heidelberg in the form of a video ethnography ensuing from two years of work. For this collection of essays, Shrum and his colleagues retold the basic story line and critically reflected upon the ways in which the original video ethnography was received by the audience in Heidelberg. Originally, the authors had obtained U.S. National Science Foundation funds to examine 
the use of the Internet and its effects on social networks of scientists in Africa and India.

But the sites of interest in Ghana lacked Internet connectivity, so the funds were rededicated in order to provide for this basic condition of the primary research interest.

The study shows that new information and communication technologies, depending on the quality of the services, seem to be of ambiguous value for some academics working in Ghana. It also reveals that external funding from the U.S. team was identified by other Ghanaians — quite independently of the American project membersas a means for making money rather than for making progress toward Internet connectivity. The failure of the project frustrated the authors but also gave rise to a wonderful academic friendship with a Ghanaian lecturer in sociology. This outcome highlights two points: (a) the contingency of transnational academic exchange and (b) the fact that the spaces of science often taken for granted by academics are in fact very fragile, difficult to achieve and sustain, and geographically very concentrated.

In this section's final paper, which is based on ethnographic fieldwork in Rabat and Hanover, ethnographer Alexa Färber (Chapter 9) also discusses relationships between the global South and the global North. However, she explores the design of space for knowledge consumption by analyzing the ways in which a team of former politicians, diplomats, civil servants, government advisors, architects, and academics (including two geographers) constructed Morocco's representation at EXPO 2000 in Hanover. The author elaborates the reasons why the committee members responsible for the country's "representational work" did not address the realities of modern Morocco with technological media but instead undertook to anticipate the visitors' expectations as potential tourists and therefore concentrated on displaying cultural heritage through "artisans, folklore, and artifacts." Färber argues that drawing on the oriental and worldfair aesthetic archives in order to live up to "Western fantasy" not only rendered the "new 
smartness" of Morocco's knowledge society invisible but reproduced knowledge divides between a smart global North and an ignorant global South. Her article therefore demonstrates that the public influenced the production of geographical knowledge so much that it shaped the reasoning of the academic experts involved in designing Morocco's self-presentation on an international stage.

In a series of articles written by geographers, this book's final section, "Science and the Public," further explores important interactions between these two realms. Using newspaper reports and other written sources dating from the period 1845 to 1939 , Charles W. J. Withers (Chapter 10) provides a historical perspective on how the public received the peripatetic annual scientific meetings of the British Association for the Advancement of Science. He illustrates how the attendance at and reaction to presentations varied considerably, depending on complex issues such as the differences between the BAAS's different thematic sections, "popular" and "scientific" presentations, more and less prolific speakers, those using lantern slides and those who did not visually support their stories, the local audiences' perceptions of the Association's objectives, and gender. The author holds that the interaction with the public at the BAAS meetings was often more akin to "participating in a civic social gathering" than to a genuine interest in the content of science. But he also asserts that it would be misleading to speak of a homogenous public, for the documented variations in attendance, reception, and understanding tend to bear out the concept of a historically and geographically contingent relationship between heterogeneous sciences and multiple publics.

Alexander Vasudevan (Chapter 11) takes the reader to Weimar Germany, where he explores the relationship between modernist art experiments and the experimental life sciences, particularly "psychiatric science." The first of his two case studies shows how Berlin Dada used the stylistic device of montage to transport the issue of war neurosis 
"from the trenches and clinics to the sites and venues of postwar metropolitan culture" and to address the physical and mental consequences of "the shock of urban industrial modernity." The second case study investigates the ways in which psychotechnics widely employed to raise workplace efficiency were used in Brechtian epic theater to transform the audience from test subjects in everyday life into informed experts in the theater. Although Brecht's 1931 production of Mann ist Mann was rather critically received by the audiences, experimental psychiatry "furnished Berlin Dada and Brechtian epic theater with a new repertoire of performance styles and representational techniques," creating an "alternative experimental program" that contested mainstream German psychiatry. His article thus suggests that both performative art and political theater offer "a critical perspective on the extension of the experimental into nonscientific zones."

Sally Eden's essay (Chapter 12) looks at contemporary interactions between science and the public by exploring the ways in which NGOs engage with science when advancing their agendas for environmental reform. Adopting Gieryn's concept of "boundary work" (Gieryn, 1983), she maintains that NGOs complicate the simplistic dichotomy between scientific experts and "a supposedly lay public" in many ways, such as by recruiting more and more researchers with postgraduate degrees and by enrolling scientists who support their moral agenda. Some NGOs go beyond bridging work by deliberately creating hybrid spaces of "heterogeneous knowledge practices" for their purposes, as when they draw on an international panel of scientific experts and environmental practitioners. Eden suggests that these hybridizations are not only variously successful but also highly specific in time and space. A British example relates to the Forest Stewardship Council's national standards governing the acceptable use and types of pesticides, the revision of which every five years is based on the latest research findings. The boundaries of these hybrid lay-expert knowledge spaces appear to be much 
more dynamic, fuzzy, and blurred than those of the modernist dichotomies between science and politics that they undermine. One can thus regard the former kind of boundaries as more flexible than the latter kind for both challenging and building alliances with science in environmental policy debates.

The final essay of this book, written by Ryan Holifield (Chapter 13), begins by calling attention to the contested nature of such hybrid knowledge spaces. Specifically, he points out that the practices of risk assessment as conducted by the U.S. Environmental Protection Agency (EPA) have been severely criticized by both regulated industries (for being overly protective) and environmental activists (for not being protective enough). He focuses on regulatory science as opposed to academic science in his discussion of how the debates about localizing the procedures of human health risk assessment in Indian Country in the United States have developed since the 1980s. Drawing on Latour's concept of collectives of humans and nonhumans, which corresponds well to tribal, or nonmodern, traditional worldviews of integrated human communities and nonhuman environments, Holifield explains why tribal traditional lifeways escape the EPA's standard risk assessment procedures attuned to typical suburban populations. In other words, they require attention to the voices of locally distinctive publics as "nations within.” He argues that regulatory science must engage with multiple publics as well as human and nonhuman collectives in order to secure credibility and legitimacy.

In conclusion, the pluralization and multiplicity of science and the public, scientific centers and designs, as well as concepts and approaches run as a central theme through the main sections of this book, highlighting the spatial and temporal complexity and contingency of past, present, and future interdisciplinary geographies of science. Our abiding thanks go to the Klaus Tschira Foundation for generously funding the symposia and book series on Knowledge and Space and for thereby making this productive 
H. Jöns, D. N. Livingstone, \& P. Meusburger, "Interdisciplinary Geographies of Science,"

Introduction to Geographies of Science, ed. D. Antal, 25June09/HJ05July09/DA18AugJuly09Final

interdisciplinary encounter possible. We are also grateful to Edgar Wunder, Christiane

Marxhausen, and their team in Heidelberg for organizing the symposia and assisting with the production of this book and to David Antal for his thoughtful contributions as the technical editor of this book series. 


\section{References}

Anderson, B., Kearnes, M., \& Doubleday, R. (2007). Geographies of nano-technoscience. Area, 39, 139-142.

Ash, A., \& Cohendet, P. (2003). Architectures of knowledge: Firms, capabilities and communities. Oxford: Oxford University Press.

Barnes T. J. (1998). A history of regression: Actors, networks, machines, and numbers. Environment and Planning A, 30, 203-223.

Barnes T. J. (2001). 'In the beginning was economic geography': A science studies approach to disciplinary history. Progress in Human Geography, 25, 455-478.

Bingham, N. \& Thrift, N. (2000). Some new instructions for travellers: The geography of Bruno Latour and Michel Serres. In M. Crang \& N. Thrift (Eds.), Thinking space (pp. 281-301). London: Routledge.

Bravo, M. T. (1999). Ethnographic navigation and the geographical gift. In D. N. Livingstone \& C. W. J. Withers (Eds.), Geography and enlightenment (pp. 199235). Chicago: University of Chicago Press.

Castells, M. (1996). The information age: Vol. 1. The rise of the network society. Oxford, England: Blackwell.

Castree, N., \& Nash, C. (2006). Editorial: Posthumanist geographies. Social and Cultural Geography, 7, 501-504.

Demeritt, D. (1996). Social theory and the reconstruction of science and geography. Transactions of the Institute of British Geographers, New Series, 21, 483-503.

Demeritt, D. (2006). Science studies, climate change and the prospects for constructivist critique. Economy and Society, 35, 453-479.

Driver, F. (2001). Geography militant: Cultures of exploration and empire. Oxford, England: Blackwell. 
Finnegan, D. (2008). The spatial turn: Geographical approaches in the history of science. Journal of the History of Biology, 41, 369-388.

Gieryn, T. F. (1983). Boundary-work and the demarcation of science from non-science: Strains and interests in professional ideologies of scientists. American Sociological Review, 48, 781-795.

Haraway, D. (1988). Situated knowledges: The science question in feminism and the privilege of partial perspective. In M. Biagioli (Ed.), The science studies reader (pp. 172-188). New York: Routledge.

Harris, S. J. (1998). Long-distance corporations, big sciences, and the geography of knowledge. Configurations, 6, 269-304.

Jöns, H. (2006). Dynamic hybrids and the geographies of technoscience: Discussing conceptual resources beyond the human/non-human binary. Social and Cultural Geography, 7, 559-580.

Livingstone, D. N. (1995). The spaces of knowledge: Contributions towards a historical geography of science. Environment and Planning D: Society and Space, 13, 5-34.

Livingstone, D. N. (2002). Science, space and hermeneutics (Hettner Lectures Vol. 5).

Heidelberg: Department of Geography.

Livingstone, D. N. (2003). Putting science in its place: Geographies of scientific knowledge. Chicago: University of Chicago Press.

Lux, D., \& Cook, H. (1998). Closed circles or open networks? Communicating at a distance during the scientific revolution. History of Science, 36, 179-211.

Meusburger, P. (2008). The nexus of knowledge and space. In P. Meusburger (Series Ed.) \& P. Meusburger, M. Welker, \& E. Wunder (Eds.), Knowledge and space: Vol. 1. Clashes of knowledge: Orthodoxies and heterodoxies in science and religion (pp. 35-90). Dordrecht: Springer. 
Murdoch, J. (1997). Towards a geography of heterogeneous associations. Progress in Human Geography, 21, 321-337.

Naylor, S. (2005). Introduction: Historical geographies of science: Places, contexts, cartographies. British Journal for the History of Science, 38, 1-12.

Philo, C., \& Pickstone, J. (2009). Unpromising configurations: Towards local historical geographies of psychiatry. Health and Place, 15, 649-656.

Powell, R. C. (2007). Geographies of science: Histories, localities, practices, futures. Progress in Human Geography, 31, 309-329.

Roe, E. J., \& Greenhough, B. (2006). Editorial: Towards a geography of bodily technologies. Environment and Planning A, 38, 416-422.

Shapin, S. (1995). Here and everywhere: Sociology of scientific knowledge. Annual Review of Sociology, 21, 289-321.

Shapin, S. (1998). Placing the view from nowhere: Historical and sociological problems in the location of science. Transactions of the Institute of British Geographers, New Series, 23, 5-12.

Simões, A., Carneiro, A., \& Diogo, M. P. (2003). Travels of learning: A geography of science in Europe. Dordrecht: Kluwer Academic Publishers.

Smith, C., \& Agar, J. (Eds.). (1998). Making space for science: Territorial themes in the shaping of knowledge. Basingstoke: Macmillan.

UCL (University College London). (Ed.). (2008). Locating Technoscience On-line Reader. Retrieved May 29, 2009, from UK Internet: http://www.ucl.ac.uk/sts/locating-technoscience Version 1.0

Wallerstein, I. (2004). World-systems analysis: An introduction. Durham, NC: Duke University Press.

Whatmore, S. (2002). Hybrid geographies: Natures cultures spaces. London: Sage. 
H. Jöns, D. N. Livingstone, \& P. Meusburger, "Interdisciplinary Geographies of Science,"

Introduction to Geographies of Science, ed. D. Antal, 25June09/HJ05July09/DA18AugJuly09Final

Withers, C. W. J. (2001). Geography, science and national identity: Scotland since 1520. Cambridge: Cambridge University Press.

Withers, C. W. J. (2002). The geography of scientific knowledge. In N. A. Rupke (Ed.), Göttingen and the development of the natural sciences (pp.9-18). Göttingen: Wallstein. 